\title{
Language activities in a minority-majority language context: book-reading at home is more important for Frisian than for Dutch
}

\author{
Evelyn BOSMA ${ }^{1 \star}$ and Elma BLOM ${ }^{2}$ \\ ${ }^{1}$ Leiden University Centre for Linguistics, Leiden University, Leiden, The Netherlands and ${ }^{2}$ Special \\ Education: Cognitive \& Motor Disabilities, Department of Education \& Pedagogy, Utrecht University, \\ Utrecht, The Netherlands \\ ${ }^{*}$ Corresponding author. P.N. van Eyckhof 1, 2311 BV Leiden, The Netherlands. \\ E-mail: e.bosma@hum.leidenuniv.nl
}

(Received 8 May 2018; revised 8 October 2018; accepted 20 December 2018; first published online 18 February 2019)

\begin{abstract}
Previous research has shown that in a minority-majority language context, the quantity of language input at home is more important for the development of the minority language than for the development of the majority language. In the current study, we examined whether the same holds true for the frequency of specific language activities at home. In a group of five- and six-year-old Frisian-Dutch bilingual children $(n=120)$, we investigated to what extent vocabulary and morphology knowledge were predicted by reading activities, watching TV, and story-telling activities in both languages. The results showed that reading in Frisian predicted both Frisian vocabulary and morphology, while reading in Dutch only predicted Dutch vocabulary. This shows that reading at home is most important for the development of the minority language. This especially holds true for the acquisition of Frisian morphology, a domain that is known to be vulnerable in language acquisition.
\end{abstract}

Keywords: vocabulary acquisition; grammar acquisition; input; bilingualism; book-reading

\section{Introduction}

Children acquire their home language by being frequently exposed to it (Hoff, 2006). As bilingual children have to divide their exposure time between two languages, they usually acquire these individual languages at a slower rate than their monolingual peers (Pearson, Fernandez, \& Oller, 1993; Uccelli \& Páez, 2007). The overall rate of language development, however, is similar to that of monolingual children (Pearson et al., 1993). Several studies show that the rate at which bilingual children acquire vocabulary is predicted by the amount of exposure to each language (Pearson, 2007; Thordardottir, Rothenberg, Rivard, \& Naves, 2006).

For children who grow up in a context with a minority and a majority language, the quantity of the input at home is especially important for the development of the minority

( ) The Author(s) 2019. This is an Open Access article, distributed under the terms of the Creative Commons Attribution licence (http://creativecommons.org/licenses/by/4.0/), which permits unrestricted re-use, distribution, and reproduction in any medium, provided the original work is properly cited. 
language (De Houwer, 2007; Dijkstra, Kuiken, Jorna, \& Klinkenberg, 2016; Gathercole \& Thomas, 2009; Hammer, Davison, Lawrence, \& Miccio, 2009). A minority language is a language that is spoken by a numerically and politically non-dominant group of people who seek to preserve their own linguistic, and usually also cultural, identity. It differs from the majority language, that is, the language that is spoken by the majority of the inhabitants of a given country (Hogan-Brun \& Wolff, 2003). As the majority language usually has a more dominant place in society than the minority language, the development of the minority language depends more on language exposure at home than the development of the majority language, which can also be learned outside the home (Dijkstra et al., 2016; Gathercole \& Thomas, 2009).

Besides input QUANTITY, input QUALITY also has an effect on children's language acquisition. While the term 'quantity' refers to the amount of exposure that children receive in a particular language, the term 'quality' refers to the diversity of words and syntactic input that they are exposed to (Rowe, 2012). Previous research has shown that, on top of input quantity, the diversity of the input also has an effect on children's language development (Huttenlocher, Waterfall, Vasilyeva, Vevea, \& Hedges, 2010; Rowe, 2012). One way to create a linguistically diverse environment is to involve children in language activities such as book-reading and oral story-telling. Children who are read to on a regular basis have larger vocabularies than children who are read to only rarely or not at all (Mol \& Bus, 2011). In bilingual children, language activities such as reading and oral story-telling can stimulate vocabulary development in both languages (Scheele, Leseman, \& Mayo, 2010). In addition, there are indications that shared book-reading also promotes grammatical development (Sénéchal, Pagan, Lever, \& Ouellette, 2008). So far, it has not been investigated, however, whether language activities in the home are equally important for the development of vocabulary and grammar in both the minority and the majority language of bilingual children. As the quantity of the input at home is more important for the minority language (De Houwer, 2007; Dijkstra et al., 2016; Gathercole \& Thomas, 2009; Hammer et al., 2009), this may also be the case for the frequency with which children are involved in specific language activities at home. In the current study, we examined to what extent the development of vocabulary and morphology in five- and six-year-old Frisian-Dutch bilingual children was predicted by the engagement in different language activities in the home (book-reading, oral story-telling, and watching TV). We investigated this for both Frisian (the minority language) and Dutch (the majority language). In what follows, we will first discuss the effect of language activities on language acquisition in more detail. Subsequently, we will provide more information about the Frisian-Dutch bilingual language setting.

\section{Language activities at home}

The three language activities that we focused on in the current study are book-reading, oral story-telling, and watching TV. In this section, we will discuss each of these three activities separately and show how they are relevant for input quality. It is important to note that much more is known about book-reading than about oral story-telling and watching TV.

\section{Book-reading}

A large number of studies have reported a positive relationship between shared book-reading and vocabulary development (e.g., DeBaryshe, 1993; Houston-Price, Howe, \& Lintern, 2014; Khu, Graham, \& Ganea, 2014; Patterson, 2002; Prevoo et al., 
2014; Scheele et al., 2010; Sénéchal, 1997). This relationship has been confirmed by a number of meta-analyses (Bus, Van IJzendoorn, \& Pellegrini, 1995; Mol \& Bus, 2011; Mol, Bus, De Jong, \& Smeets, 2008; National Center for Family Literacy, 2008) and has been found across different age groups (Mol \& Bus, 2011), in both low- and high-ability readers (Mol \& Bus, 2011), and not only in monolingual children, but also in bilingual children (Patterson, 2002; Scheele et al., 2010).

While the effect of reading on vocabulary is well established, only a few studies have investigated the effect of book-reading on grammatical development (Crain-Thoreson \& Dale, 1992; Cronan, Cruz, Arriaga, \& Sarkin, 1996; Sénéchal et al., 2008; Whitehurst et al., 1988). These studies do show positive effects. Crain-Thoreson and Dale (1992) found that shared book-reading predicted syntactic comprehension at age 2;6, and Sénéchal and colleagues (2008) found that shared book-reading predicted morphological knowledge at age four. Whitehurst and colleagues (1988) found that a one-month book-reading intervention with two-year-olds resulted in an increase in children's mean length of utterance, and in a book-reading intervention study with one- to three-year-olds, Cronan and colleagues (1996) observed gains in grammatical complexity. These results indicate that book-reading activities have a positive effect on grammar acquisition. Still, the impact of shared book-reading on grammar seems to be smaller than the impact on vocabulary (National Center for Family Literacy, 2008). Furthermore, as far as we know, there are no studies on the effect of book-reading on the grammatical development of bilingual children in both of their languages.

There are several factors that may explain the enhancing effect of book-reading. One important factor is that books offer greater lexical diversity (Montag, Jones, \& Smith, 2015) and more grammatically rich constructions (Noble, Cameron-Faulkner, \& Lieven, 2018) than child-directed speech that does not involve book-reading. Montag and colleagues (2015) not only showed that the words within a single picture-book are usually more diverse than the words within a single conversation between a parent and a child, but also that the individual books that parents read are likely to be more different from one another than the conversations that they have with their children. Noble and colleagues (2018) found more grammatically rich constructions in child-directed speech generated by shared book-reading than in child-directed speech generated by toy play. Furthermore, they observed that the type of book affected the grammatical richness of the child-directed speech generated by shared book-reading.

In addition to increasing the richness of the input, book-reading may lead to more moments of joint attention (Fletcher, Cross, Tanney, Schneider, \& Finch, 2008). Joint attention refers to coordinating attention between interactive social partners towards objects or events (Mundy, Sigman, Ungerer, \& Sherman, 1986). In the context of language development, and specifically word learning, joint attention may provide the child with information about the intended referent (Tomasello \& Farrar, 1986), and has been found to positively affect language learning (Farrant \& Zubrick, 2012, 2013).

\section{Oral story-telling}

Story-telling that does not involve books, such as family mealtime conversations, has also been shown to have a positive effect on vocabulary acquisition (Beals, 2001; Curenton, Craig, \& Flanigan, 2008; Katz, 2001; Rowe, 2013). Rowe (2013) found that preschoolers whose parents provided them with more explanations and narratives 
about past or future events had larger vocabularies than preschoolers whose parents provided them with less of these types of oral story-telling. In a group of five-year-old children, Beals (2001) found significant positive correlations between parents' use of explanations and narratives during family mealtimes and children's receptive vocabulary scores and their abilities to give definitions of words. Furthermore, there was a significant positive correlation between parents' use of narrative utterances and children's story comprehension. Katz (2001) found that parents' use of pretend utterances while playing with their three-year-olds related to children's receptive vocabulary and their skill at providing formal definitions in kindergarten. A recent study that focused on children's oral story-telling instead of parents' oral story-telling showed that children who produced a larger proportion of explanations, narratives, and pretend utterances at age 2;6 had significantly higher levels of academic language proficiency at the age of twelve (Uccelli, Demir-Lira, Rowe, Levine, \& Goldin-Meadow, 2018). Not surprisingly, children's production of oral story-telling is very strongly associated with their parents' production of oral story-telling (Demir, Rowe, Heller, Goldin-Meadow, \& Levine, 2015).

An important factor that may explain the effect of oral story-telling on language development is the use of decontextualized speech (Curenton et al., 2008; Rowe, 2013), which focuses on people, objects, concepts, or events that are not present in the immediate surroundings. During decontextualized conversations, children cannot rely on pointing or other non-verbal cues, which means that they can only make use of the language itself to understand and convey meaning. As a result, decontextualized speech contains more diverse vocabulary and more complex morphosyntactic structures than contextualized speech, which makes it an important predictor for language development (Demir et al., 2015; Reese, 1995; Rowe, 2012, 2013; Uccelli et al., 2018).

\section{Watching TV}

While book-reading and oral story-telling are clearly positively associated with vocabulary development, findings on the effects of watching TV are mixed. While most studies did not find a relationship between the frequency of watching TV and vocabulary acquisition (Hudon, Fennell, \& Hoftyzer, 2013; Patterson, 2002; Schmidt, Rich, Rifas-Shiman, Oken, \& Taveras, 2009; Zimmerman, Chistakis, \& Meltzoff, 2007), Chonchaiya and Pruksananonda (2008) found a negative relationship. They showed that children who had started watching TV before their first birthday and who watched TV more than two hours a day were approximately six times more likely to develop language delays than children who did not meet these criteria. Possible explanations for these negative and null results are the lack of social interactions and familiar contexts (Patterson, 2002) and the lack of opportunity to interact in activities that are more beneficial for language acquisition (Chonchaiya \& Pruksananonda, 2008).

Taken together, the literature shows that book-reading and oral story-telling have a positive effect on vocabulary development, not only in monolingual children (e.g., Mol \& Bus, 2011; Uccelli et al., 2018), but also in bilingual children (Patterson, 2002; Scheele et al., 2010). The results on the effect of watching TV are mixed (Chonchaiya \& Pruksananonda, 2008; Hudon et al., 2013). With respect to grammatical development, there are some indications that book-reading has a positive effect in monolingual children (e.g., Sénéchal et al., 2008), but it is unknown 
how book-reading affects grammatical development in bilingual children. Furthermore, it has so far not been investigated whether oral story-telling has the same positive effect on grammar acquisition as book-reading, and how the combination of book-reading, oral story-telling and watching TV affects language acquisition.

\section{The Frisian-Dutch bilingual context}

In the current study, we investigated the effect of language activities in the home on the language acquisition of Frisian-Dutch bilingual children. In the Dutch province of Fryslân, both Dutch, the national majority language, and Frisian, the regional minority language, have official status. Outside the Netherlands, Frisian is referred to as West Frisian to distinguish it from the Frisian languages that are spoken in Germany. In the current study, whenever the term Frisian is used, it refers to the West Frisian language.

In the European Charter for Regional and Minority Languages (ECRML), which came into force in 1998, Frisian is recognized under part III. This means that, in domains like education, administration, and the media, the Dutch government is obliged to take practical measures for the promotion of Frisian. In 2005, Frisian obtained recognition from the Dutch government as the only national minority language under the Framework Convention on the Protection of National Minorities. Finally, in 2014, the Wet Gebruik Friese Taal 'Law on the use of the Frisian language' came into effect in the Netherlands, stating that Frisian and Dutch are the official languages of the province of Fryslân.

The province of Fryslân has approximately 650,000 inhabitants (Centraal Bureau voor Statistiek, 2018). In the most recent language survey of the province, a bit more than half of the population reported speaking Frisian as a mother tongue (55.3\%) and a bit less than half of the population reported speaking Frisian with their partner (45.6\%) and children (47.5\%) (Provinsje Fryslân, 2015). Although this survey shows that Frisian still has quite a strong position in the province as a whole, it must be said that Frisian is much stronger in rural than in urban areas and that it is predominantly used in informal domains (Breuker, 2001). Furthermore, the survey shows that Frisian is used more as an oral than as a written language: whereas the majority of the population reported speaking Frisian well $(66.6 \%)$, only a bit more than half of the population reported reading it well (51.8\%), and only a small minority reported writing it well (14.5\%) (Provinsje Fryslân, 2015).

Despite the observation that most inhabitants of Fryslân are not literate in Frisian, the production of books in Frisian is relatively large: each year, approximately 100 Frisian books are published, including books for children. Furthermore, there are a few literary periodicals, like the monthly De Moanne, that are published in Frisian, but these have a limited distribution. There are no daily or weekly newspapers in Frisian, but regional daily newspapers like the Leeuwarder Courant do use Frisian in some articles. Furthermore, the regional broadcaster Omrop Fryslân broadcasts an hour and a half of regional television per day and more than 80 hours of regional radio per week, and there is also school radio and school television for 20 minutes per week (De Graaf, Van der Meer, \& Karsten, 2013).

In education, Dutch is clearly the dominant language, although there is a law from 1955 that allows Frisian-Dutch bilingual schools (Mercator, 2007), and more and more primary schools have become trilingual (third language: English) in the Trijetalige skoalle (trlingual school) project (Van Ruijven \& Ytsma, 2008). Under the ECRML 
part III, primary schools in Fryslân are required to teach Frisian as a subject for at least one hour per week, and many schools also have Frisian as one of the languages of instruction. Previous research on Frisian vocabulary development has shown that even children with minimal to no Frisian exposure at home have some knowledge of Frisian vocabulary (Bosma, Blom, Hoekstra, \& Versloot, 2016).

Frisian is a West Germanic language, just like Dutch. Although Frisian was historically more closely related to English, it has become more similar to Dutch due to intensive language contact (Gooskens \& Heeringa, 2004). As a result of this language contact situation, the Frisian and Dutch languages that are spoken today share a large proportion of their lexicons and morphosyntactic structures. The many cognates that the two languages share make Frisian-Dutch bilingual vocabulary acquisition relatively easy (Bosma et al., 2016; Bosma, Heeringa, Hoekstra, Versloot, \& Blom, 2017). There are, however, still some structural differences between the two languages, for example in the domain of nominal and verbal morphology. With respect to nominal morphology, Frisian has a closed set of nouns in which breaking occurs in the plural and diminutive form (e.g., foet-fuotten 'foot-feet'). Breaking is a relatively opaque rule that involves the alternation of rising and falling diphthongs. As all plural and diminutive forms also have a plural or diminutive suffix, breaking is functionally redundant, making it harder to learn (Ytsma, 1995, pp. 39-40). With respect to verbal morphology, Frisian has two types of regular verbs, infinitives that end in $-e$ (e.g., fytse 'to cycle') and infinitives that end in -je (e.g., dînsje 'to dance'). Participles of the first type are formed by adding the suffix - $t$ (fytse-fytst 'to cycle-cycled') or $-d$ (draaie-draaid 'to turn-turned') to the stem, while participles of the second type are formed by adding the suffix $-e$ (dînsje-dînse 'to dance-danced'). Dutch, in contrast, only has regular verbs with an infinitive that ends in -en and a participle that is formed with a circumfix $g e \_t / d$ (dansen-gedanst 'to dance-danced'). As a result of relatively limited input in Frisian outside the home, even children with Frisian as their first language struggle with the acquisition of these structural aspects of Frisian (Ytsma, 1995, p. 120).

With respect to input quantity, previous research on Frisian-Dutch bilingual children has shown that the quantity of the input at home is especially important for the development of Frisian (Bosma, Hoekstra, Versloot, \& Blom, 2017; Dijkstra, 2013; Dijkstra et al., 2016; Van Ruijven, 2006; Ytsma, 1995, 1999). Dijkstra (2013) showed that preschoolers (age $2 ; 6$ to 4;0) with Frisian as their home language performed as well as preschoolers with Dutch as their home language on several Dutch language measures, including receptive vocabulary, lexical diversity, and mean length of utterance. Their performance on Dutch productive vocabulary was lower, however. On the Frisian equivalents of these tasks, in contrast, children with Dutch as their home language obtained significantly lower scores than their peers with Frisian as their home language. Ytsma (1999) showed that, in the first year of primary school (age four and five), children with Frisian as their home language made more progress in Dutch than children with Dutch as their home language made progress in Frisian. Towards the end of the first year, the former group had a more balanced proficiency in the two languages than the latter group. Similarly, Bosma, Hoekstra, Versloot, and Blom (2017) showed that intensity of exposure to Frisian at home predicted to a large extent whether schoolchildren (age five to eight) had a balanced proficiency in their two languages. Van Ruijven (2006) showed that, by the fourth year of primary school (age seven and eight), children with Frisian as their home language were no longer behind in Dutch compared to their monolingual 
peers in the rest of the Netherlands. Children with Dutch as their home language, in contrast, did not catch up in Frisian compared to their peers with Frisian as their home language (Ytsma, 1995). Taken together, these studies show that the quantity of the input at home is much more important for Frisian than it is for Dutch.

In the current study, we investigated whether the same holds true for the frequency with which children are involved in specific language activities in the home, and whether some language activities are more important than others. More specifically, we investigated to what extent Frisian and Dutch book-reading, oral story-telling, and watching TV at home predict children's Frisian and Dutch vocabulary and grammar development. As previous research has shown that the quantity of the input is more important for Frisian than for Dutch, we expected that this would also be the case for the quality of the input. We tentatively predicted that language activities in Frisian would be especially important for those domains of the Frisian language where children experience the greatest difficulty, namely structural aspects like nominal and verbal morphology (Ytsma, 1995). Given previous literature on the effect of reading on grammatical development (Crain-Thoreson \& Dale, 1992; Cronan et al., 1996; Sénéchal et al., 2008; Whitehurst et al., 1988), we expected book-reading to be the most important language activity for the acquisition of Frisian morphology.

\section{Method}

\section{Participants}

Participants were recruited through primary schools in the countryside of the Dutch province of Fryslân. The 14 schools that agreed to participate distributed information folders and consent forms among the parents of the five- and six-year-old children. Only children whose parents had signed the consent form were included in our study ( $n=120,59$ boys, 61 girls). Table 1 provides information about children's background variables, including age, socioeconomic status (SES), intensity of exposure to Frisian at home, and non-verbal IQ scores. As SES (Hoff, 2003), intensity of exposure (Pearson, 2007; Thordardottir et al., 2006), and non-verbal IQ (Rice \& Hoffman, 2015) have previously been found to influence language acquisition, these were included as control variables in the present study.

Information about age, SES, and intensity of exposure to Frisian was obtained through a parental questionnaire, based on the Questionnaire for Parents of Bilingual Children (PaBiQ; Tuller, 2015), which is based on the Alberta Language Development Questionnaire (ALDeQ; Paradis, Emmerzael, \& Sorenson Duncan, 2010), and the Alberta Language Environment Questionnaire (ALEQ; Paradis, 2011). SES was calculated as the average educational level of the mother and the father, as measured on a 9-point scale: (1) no education, (2) elementary education, (3) pre-vocational secondary education, (4) pre-vocational secondary education, theoretical programme, (5) vocational education, level 2 or 3, (6) vocational education, level 4, (7) higher secondary education, (8) higher professional education, (9) university degree. Intensity of exposure to Frisian was calculated as the mean percentage of Frisian input that the child received from his mother, father, siblings, and other adults who took care of the child at least once per week. The type of interaction was not specified and the answer could thus also include shared reading and oral story-telling. For each of these people we asked how often (s)he spoke Frisian to the 
Table 1. Descriptive statistics of the participants

\begin{tabular}{|c|c|c|c|c|}
\hline Measure & $n$ & Mean (SD) & Range & Maximum possible score \\
\hline Age & 120 & $5 ; 10(0 ; 7)$ & $4 ; 11-6 ; 11$ & \\
\hline SES & 120 & $6.9(1.3)^{1}$ & $3.5-9$ & 9 \\
\hline \% Frisian exposure & 120 & $63(29)$ & $0-100$ & 100 \\
\hline$\%$ Dutch exposure & 120 & $37(29)$ & $0-100$ & 100 \\
\hline Non-verbal IQ & 120 & $106(15)$ & $73-144$ & 144 \\
\hline
\end{tabular}

child: 'never' (0\%), 'seldom' (25\%), 'sometimes' (50\%), 'usually' (75\%), or 'always' $(100 \%)$, and then we averaged the answers. The same question was asked for Dutch. In cases where the Frisian and Dutch scores did not add up to $100 \%$, we recalculated the percentage scores by taking the sum of the Frisian and Dutch scores, dividing the Frisian score by the total sum and then multiplying this by 100 , so that the sum of intensity of exposure to Frisian and intensity of exposure to Dutch did add up to $100 \%$. Non-verbal IQ was measured with the subsets Matrices and Recognition of the Wechsler Non-verbal Scale of Ability (WNV; Wechsler \& Naglieri, 2006).

\section{Measures}

Frisian and Dutch receptive vocabulary

Dutch receptive vocabulary was measured with the Peabody Picture Vocabulary Test-III-NL (PPVT-III-NL; Schlichting, 2005), which is the Dutch version of the PPVT-III (Dunn \& Dunn, 1997). In order to measure Frisian receptive vocabulary, we developed an adaptation of the PPVT-III-NL (Bosma et al., 2016). In these receptive vocabulary tasks, children heard a stimulus word and had to choose the correct referent out of four pictures. The PPVT-III-NL contains 17 sets of 12 items, and the sets are ordered by difficulty. For the Frisian adaptation, we only translated the first 12 sets, that is, the first 144 items, as these sets suffice to measure the vocabulary knowledge of five- and six-year-old children. In order to make the Frisian and Dutch vocabulary task comparable, we also only used the first 12 sets for Dutch. To ensure that the scores on the Frisian and Dutch task were based on an equal number of items, we did not use basal and ceiling criteria, which means that the children had to answer all items for both Frisian and Dutch. They received one point for each correct answer.

\section{Frisian and Dutch expressive morphology}

Dutch expressive morphology was measured with the subtest Word Formation of the Taaltoets Alle Kinderen 'Language assessment all children' (Verhoeven \& Vermeer, 2002). This task contains 12 items that test noun plural formation and 12 items that test past participle formation. For the elicitation of noun plurals, children are presented with pictures of objects and prompt sentences of the following type: Dat is een $X$, dat zijn twee ... 'This is an $\mathrm{X}$, these are two ...'. For the elicitation of past participles, children are presented with pictures of actions and prompt sentences of 
the following type: Rosita is een bal aan het gooien. Gisteren heeft zij ook al een bal ... 'Rosita is throwing a ball. Yesterday she has also ... a ball'. In order to measure Frisian expressive morphology, we developed a comparable task for the purpose of this project (Blom \& Bosma, 2016). Both the Frisian and the Dutch task contained items with different degrees of regularity in both the noun plural and the past participle part of the task, and both tasks contained items with different degrees of lexical and morphological overlap between Frisian and Dutch. For the Frisian morphology task, this included three nouns that contain breaking in the plural form, two regular infinitives that end in $-e$, and two regular infinitives that end in $-j e$. As discussed in the section 'The Frisian and Dutch bilingual context', plural formation of Frisian nouns with breaking and participle formation of Frisian regular verbs are known to be difficult, even for children with Frisian as their home language (Ytsma, 1995, p. 120). As in the vocabulary tasks, the children received one point for each correct answer.

\section{Language activities at home}

Information about children's language activities at home was obtained through the PaBiQ (Tuller, 2015). For both Frisian and Dutch, we asked the parents how often the children were involved in book-reading, oral story-telling, and watching TV. For each of these three activities, possible answers were '(almost) never' (0), 'at least once a week' (1), and 'every day' (2).

\section{Procedure}

The tasks in this study were part of a larger test battery that included language and cognitive tasks that were not reported on in the present study. Children were tested in a quiet room at school, except for one child, who was tested at home. The children were tested by the first author or a research assistant, who both had a native-level command of Frisian and Dutch. The tasks were divided over two sessions of about 60 minutes each with at least five days in between the two sessions. They were administered in the following order: Frisian receptive vocabulary and Frisian morphology in the first session; Dutch receptive vocabulary and Dutch morphology in the second session. We did not counterbalance the order of the languages, because it would be difficult to match the two groups on all background variables (age, SES, intensity of exposure, non-verbal IQ).

\section{Results}

Means and standard deviations for the language measures and activities are presented in Table 2. The children obtained higher scores on Dutch vocabulary than on Frisian vocabulary $(t(119)=2.69, p<.01)$, and they also obtained higher scores on Dutch morphology than on Frisian morphology $(t(119)=3.65, p<.001)$. Children were read to more often in Dutch than in Frisian $(t(119)=13.85, p<.001)$, and also watched more Dutch than Frisian television $(t(119)=29.71, p<.001)$. There were, however, no differences between frequency of story-telling in Dutch and Frisian $(t(119)=-1.76, p=.08)$.

Table 3 shows the correlations between the background variables and the Dutch and Frisian language measures and activities. No corrections to probability levels were made, because the correlations were only run for descriptive purposes and for the purpose of 
Table 2. Means and standard deviations for language measures and language activities $(n=120)$

\begin{tabular}{lccc}
\hline Measure & Mean (SD) & Range & Maximum possible score \\
\hline Frisian vocabulary & $90.69(8.87)$ & $59-110$ & 144 \\
\hline Frisian morphology & $13.09(5.32)$ & $1-23$ & 24 \\
\hline Frisian reading & $0.67(0.67)$ & $0-2$ & 2 \\
\hline Frisian TV & $0.28(0.53)$ & $0-2$ & 2 \\
\hline Frisian story-telling & $1.26(0.90)$ & $0-2$ & 2 \\
\hline & & & 144 \\
\hline Dutch vocabulary & $92.54(8.03)$ & $67-115$ & 24 \\
\hline Dutch morphology & $15.25(3.19)$ & $8-23$ & 2 \\
\hline Dutch reading & $1.65(0.53)$ & $0-2$ & 2 \\
\hline Dutch TV & $1.92(0.31)$ & $0-2$ & 2 \\
\hline Dutch story-telling & $1.00(0.93)$ & $0-2$ & \\
\hline
\end{tabular}

identifying variables to be used in subsequent regression analyses. There was a significant, negative correlation between age and reading in Frisian $(r(120)=-0.21$, $p=.02$ ), showing that younger children were read to in Frisian more often than older children. There were significant, positive correlations between SES and reading in Dutch $(r(120)=0.24, p<.01)$, and between SES and story-telling in Dutch $(r(120)=$ $0.22, p=.02$ ), showing that children of more highly educated parents were more involved in reading and story-telling activities in Dutch. There were significant, negative correlations between SES on the one hand and intensity of exposure to Frisian $(r(120)=-0.26, p<.01)$, and story-telling in Frisian $(r(120)=-0.20, p=.03)$, on the other hand, showing that children of parents with a low educational level received more input in Frisian and were more involved in story-telling activities in Frisian than children of parents with a high educational level. Furthermore, there were significant, positive correlations between intensity of exposure to Frisian on the one hand and book-reading in Frisian $(r(120)=0.25, p<.01)$, oral story-telling in Frisian $(r(120)=0.76, p<.001)$, and watching Frisian television $(r(120)=0.22, p$ $=.02$ ), on the other. With respect to intensity of exposure to Dutch, there were significant, positive correlations with book-reading in Dutch $(r(120)=0.22, p=.02)$ and oral story-telling in Dutch $(r(120)=0.68, p<.001)$.

\section{Language activities at home and Frisian and Dutch vocabulary and morphology}

The aim of this study was to investigate to what extent book-reading, oral story-telling, and watching TV predicted the development of children's receptive vocabulary and expressive morphology in Frisian and Dutch. First, we investigated to what extent Frisian language activities predicted Frisian vocabulary. The correlation matrix in Table 3 showed that there were significant correlations between Frisian vocabulary on the one hand and age $(r(120)=0.38, p<.001)$, IQ $(r(120)=0.28, p<.01)$, and intensity of exposure to Frisian $(r(120)=0.50, p<.001)$, on the other hand. Therefore, these variables were included as control variables in the follow-up 
Table 3. Correlations between background variables and Dutch and Frisian language measures and activities

\begin{tabular}{|c|c|c|c|c|c|c|c|c|c|c|c|c|c|}
\hline & 1. & 2. & 3. & 4. & 5. & 6. & 7. & 8. & 9. & 10. & 11. & 12. & 13. \\
\hline 1. Age & - & & & & & & & & & & & & \\
\hline 2. SES & -0.11 & - & & & & & & & & & & & \\
\hline 3. $\% \mathrm{FR}$ & 0.09 & $-0.26^{\star \star}$ & - & & & & & & & & & & \\
\hline 4. IQ & -0.02 & 0.06 & -0.02 & - & & & & & & & & & \\
\hline 5. DU voc & $0.43^{\star \star \star}$ & 0.03 & 0.04 & $0.25^{\star \star}$ & - & & & & & & & & \\
\hline 6. DU mor & 0.16 & $0.23^{*}$ & $-0.35^{\star \star \star}$ & 0.02 & $0.27^{\star \star}$ & - & & & & & & & \\
\hline 7. DU read & -0.01 & $0.24^{\star \star}$ & $-0.22^{\star}$ & 0.14 & $0.20^{\star}$ & $0.20^{\star}$ & - & & & & & & \\
\hline 8. DU TV & 0.04 & -0.11 & -0.03 & -0.12 & -0.06 & -0.11 & 0.03 & - & & & & & \\
\hline 9. DU story & -0.03 & $0.22^{*}$ & $-0.68^{\star \star \star}$ & 0.07 & 0.02 & $0.32^{\star \star \star}$ & $0.36^{\star * *}$ & 0.00 & - & & & & \\
\hline 10. FR voc & $0.38^{\star \star \star}$ & -0.03 & $0.50^{\star \star \star}$ & $0.28^{\star \star}$ & $0.61^{\star \star \star}$ & 0.09 & 0.00 & -0.09 & $-0.29^{\star \star}$ & - & & & \\
\hline 11. FR mor & 0.04 & -0.10 & $0.70^{\star \star \star}$ & 0.12 & $0.19^{*}$ & -0.10 & -0.12 & -0.13 & $-0.53^{\star \star \star}$ & $0.47^{\star \star \star}$ & - & & \\
\hline 12. FR read & $-0.21^{\star}$ & 0.04 & $0.25^{\star \star}$ & 0.03 & 0.00 & -0.07 & 0.17 & -0.10 & $-0.19^{\star}$ & $0.19^{*}$ & $0.39^{\star \star \star}$ & - & \\
\hline 13. FR TV & -0.01 & -0.17 & $0.22^{*}$ & 0.03 & 0.04 & -0.07 & -0.07 & 0.04 & $-0.22^{\star}$ & 0.15 & $0.25^{\star \star}$ & $0.21^{*}$ & - \\
\hline 14. FR story & -0.03 & $-0.20^{\star}$ & $0.76^{\star \star \star}$ & -0.04 & -0.01 & $-0.37^{\star \star \star}$ & $-0.25^{\star \star}$ & 0.08 & $-0.54^{\star \star \star}$ & $0.32^{\star \star \star}$ & $0.67^{\star \star \star}$ & $0.33^{\star \star \star}$ & $0.25^{\star x}$ \\
\hline
\end{tabular}

Notes. ${ }^{*} p<.05 ;{ }^{* \star} p<.01 ;{ }^{* \star *} p<.001$. 
Table 4. Frisian receptive vocabulary, regressed on reading in Frisian, controlling for age, IQ, and Frisian intensity of exposure at home

\begin{tabular}{lcc}
\hline & \multicolumn{2}{c}{ Frisian receptive vocabulary } \\
\cline { 2 - 3 } & Stage $1(\beta)$ & Stage $2(\beta)$ \\
\hline Age & $.35^{\star \star \star}$ & $.38^{\star \star \star}$ \\
\hline IQ & $.29^{\star \star \star}$ & $.29^{\star \star \star}$ \\
\hline Frisian intensity of exposure at home & $.47^{\star \star \star}$ & $.43^{\star \star \star}$ \\
\hline Reading in Frisian & & $.15^{\star}$ \\
\hline $\mathrm{R}^{2}$ & .45 & .47 \\
\hline$\Delta \mathrm{R}^{2}$ & & $.02^{\star *}$ \\
\hline $\mathrm{F}$ & $31.69^{\star \star \star}$ & $25.54^{\star \star \star}$ \\
\hline
\end{tabular}

Notes. ${ }^{\star} p<.05 ;{ }^{\star \star \star} p<.001$.

regression analysis. Furthermore, the correlation matrix showed that there were significant, positive correlations between Frisian vocabulary on the one hand and book-reading in Frisian $(r(120)=0.19, p=.04)$, and oral story-telling in Frisian $(r(120)=$ $0.32, p<.001)$ on the other. In order to investigate whether these latter findings would hold when controlling for age, IQ, and intensity of exposure at home, we ran two hierarchical multiple regression analyses with Frisian vocabulary as the outcome variable. In the first stage of the model, we added age, IQ, and Frisian intensity of exposure at home as control variables. In the second stage of the model, we added book-reading in Frisian as predictor. As there was a strong, significant correlation between oral story-telling in Frisian and intensity of exposure to Frisian at home $(r(120)=0.76$, $p<.001$ ), we conducted an analysis of the variance inflation factor (VIF) to test for multicollinearity. When we ran a model with age, IQ, intensity of exposure, reading in Frisian, and story-telling in Frisian as predictors, the average VIF turned out to be 1.6, which is substantially greater than 1 and thus indicates a risk of multicollinearity (Field, 2000, p. 224). Therefore, we did not include oral story-telling in the model. As there was no significant correlation between Frisian vocabulary and watching TV in Frisian, this variable was also not included in the model. The results are shown in Table 4. Book-reading in Frisian significantly predicted Frisian vocabulary $(\beta=.15, p=.04)$.

Second, we investigated to what extent Dutch language activities predicted Dutch vocabulary. The correlation matrix in Table 3 showed that there were significant correlations between Dutch vocabulary on the one hand and age $(r(120)=0.43$, $p<.001)$ and IQ $(r(120)=0.25, p<.01)$ on the other hand. Therefore, these variables were included as control variables in the follow-up regression analysis. Furthermore, the correlation matrix showed that there was a significant, positive correlation between Dutch vocabulary and book-reading in Dutch $(r(120)=0.20, p=.03)$. In order to investigate whether this latter finding would hold when controlling for age and IQ, we ran two hierarchical multiple regression analyses with Dutch vocabulary as the outcome variable. In the first stage of the model, we added age and IQ as control variables. In the second stage of the model, we added book-reading in Dutch as predictor. As there were no significant correlations between Dutch vocabulary on the one hand and watching TV and story-telling on the other, these variables were 
Table 5. Dutch receptive vocabulary, regressed on reading in Dutch, controlling for age and IQ

\begin{tabular}{lcc} 
& \multicolumn{2}{c}{ Dutch receptive vocabulary } \\
\cline { 2 - 3 } & Stage $1(\beta)$ & Stage $2(\beta)$ \\
\hline Age & $.43^{\star \star \star}$ & $.44^{* \star *}$ \\
\hline $\mathrm{QQ}$ & $.26^{\star \star}$ & $.23^{\star \star}$ \\
\hline Reading in Dutch & & $.17^{\star}$ \\
\hline $\mathrm{R}^{2}$ & .25 & .28 \\
\hline$\Delta \mathrm{R}^{2}$ & & $.03^{\star}$ \\
\hline $\mathrm{F}$ & $19.61^{\star \star \star}$ & $14.88^{* \star *}$ \\
\hline
\end{tabular}

Notes. ${ }^{*} p<.05 ;{ }^{* \star} p<.01 ;{ }^{\star * \star} p<.001$.

not included in the model. The results are shown in Table 5. Book-reading in Dutch significantly predicted Dutch vocabulary $(\beta=.17, p=.04)$.

Third, we examined the effect of book-reading, oral story-telling, and watching TV on Frisian morphology. The correlation matrix in Table 3 showed that there was a significant correlation between Frisian morphology and intensity of exposure to Frisian $(r(120)=0.70, p<.001)$. Therefore, intensity of exposure was included as a control variable in the follow-up regression analysis. As previous research has shown that vocabulary development drives morphological development (Blom, Paradis, \& Duncan, 2012), we also inspected the correlation between Frisian morphology and Frisian vocabulary. As there was a significant, positive correlation between these two variables $(r(120)=0.47, p<.001)$, Frisian vocabulary was also included as a control variable. Furthermore, the correlation matrix showed that there were significant, positive correlations between Frisian morphology on the one hand and book-reading $(r(120)=0.39, p<.001)$, oral story-telling in Frisian $(r(120)=0.67, p<.001)$, and watching TV $(r(120)=0.25, p<.01)$ on the other hand. In order to investigate whether these latter findings would hold when controlling for intensity of exposure and Frisian vocabulary, we conducted two hierarchical multiple regression analyses with Frisian morphology as the outcome variable. In the first stage of the model, we added intensity of exposure and Frisian vocabulary as control variables. In the second stage of the model, we added book-reading and watching TV in Frisian as predictors. Again, we did not include oral story-telling, because of the risk of multicollinearity. The results are shown in Table 6. Book-reading in Frisian significantly predicted Frisian morphology $(\beta=.20, p<.01)$, but watching TV in Frisian did not $(\beta=.06, p=.35)$.

Finally, we investigated the effect of book-reading, oral story-telling, and watching TV on Dutch morphology. The correlation matrix in Table 3 showed that there were significant correlations between Dutch morphology on the one hand and SES $(r(120)=0.23, p=.01)$, intensity of exposure to Dutch $(r(120)=0.35, p<.001)$, and Dutch vocabulary $(r(120)=0.27, p<.01)$ on the other hand. Therefore, these variables were included as control variables in the follow-up regression analysis. Furthermore, there were significant, positive correlations between Dutch morphology on the one hand and book-reading in Dutch $(r(120)=0.20, p=.03)$ and oral story-telling in Dutch $(r(120)=0.32, p<.001)$ on the other hand. In order to 
Table 6. Frisian morphology, regressed on reading in Frisian, controlling for Frisian intensity of exposure at home and Frisian receptive vocabulary

\begin{tabular}{lcc}
\hline & \multicolumn{2}{c}{ Frisian morphology } \\
\cline { 2 - 3 } & Stage $1(\beta)$ & Stage $2(\beta)$ \\
\hline Frisian intensity of exposure at home & $.62^{\star \star \star}$ & $.57^{\star \star \star}$ \\
\hline Frisian receptive vocabulary & $.16^{\star}$ & $.14^{\star}$ \\
\hline Reading in Frisian & $.20^{\star \star}$ \\
\hline Watching TV in Frisian & .52 & .06 \\
\hline $\mathrm{R}^{2}$ & & .56 \\
\hline$\Delta \mathrm{R}^{2}$ & $62.42^{\star \star \star}$ & $.04^{\star \star}$ \\
\hline $\mathrm{F}$ & & $36.85^{\star \star \star}$ \\
\hline
\end{tabular}

Notes. ${ }^{\star} p<.05 ;{ }^{* \star} p<.01 ;{ }^{\star \star \star} p<.001$.

investigate whether these latter findings would hold when controlling for SES, intensity of exposure, and Dutch vocabulary, we ran two hierarchical multiple regression analyses with Dutch morphology as the outcome variable. In the first stage of the model, we added SES, intensity of exposure, and Dutch vocabulary as control variables. In the second stage of the model, we added book-reading in Dutch as predictor. As there was a strong, significant correlation between oral story-telling in Dutch and intensity of exposure to Dutch at home $(r(120)=0.68, p<.001)$, we conducted an analysis of the VIF. The results of this analysis indicated a risk of multicollinearity. Therefore, we did not include oral story-telling in the model. As there was no significant correlation between Dutch morphology and watching TV in Dutch, this variable was also not included in the model. The results are shown in Table 7. Book-reading in Dutch did not predict Dutch morphology $(\beta=.04, p=.63)$.

\section{Discussion}

In the current study, we investigated to what extent the bilingual language acquisition of five- and six-year-old Frisian-Dutch bilingual children could be predicted by the frequency with which they were engaged in book-reading, watching TV, and oral story-telling in their two languages. A higher frequency of these activities has been associated with a higher input quality (e.g., Demir et al., 2015; Montag et al., 2015; Noble et al., 2018), but it has also been shown that reading (e.g., Mol \& Bus, 2011) and oral story-telling (e.g., Uccelli et al., 2018) are more important than watching TV (e.g., Hudon et al., 2013). After controlling for potentially confounding factors, such as age, IQ, SES, and intensity of exposure at home, the results showed that reading activities in Frisian (the minority language) predicted the acquisition of both Frisian vocabulary and Frisian morphology, whereas reading activities in Dutch (the majority language) predicted the acquisition of Dutch vocabulary, but not the acquisition of Dutch morphology. These findings show that reading at home is especially important for the development of the minority language. Watching TV did not have an effect on children's language acquisition, neither in Frisian nor in 
Table 7. Dutch morphology, regressed on reading in Dutch, controlling for SES, Dutch intensity exposure at home, and Dutch receptive vocabulary

\begin{tabular}{lcc}
\hline & \multicolumn{2}{c}{ Dutch morphology } \\
\cline { 2 - 3 } & Stage $1(\beta)$ & Stage $2(\beta)$ \\
\hline SES & .14 & .13 \\
\hline Dutch intensity of exposure at home & $.33^{\star \star \star}$ & $.32^{\star}$ \\
\hline Dutch receptive vocabulary & $.28^{\star \star}$ & $.27^{\star \star}$ \\
\hline Reading in Dutch & & .04 \\
\hline $\mathrm{R}^{2}$ & .22 & .23 \\
\hline$\Delta \mathrm{R}^{2}$ & & .00 \\
\hline $\mathrm{F}$ & $11.15^{\star \star \star}$ & $8.37^{\star \star \star}$ \\
\hline
\end{tabular}

Notes. ${ }^{\star} p<.05 ;{ }^{* \star} p<.01 ;{ }^{* \star *} p<.001$.

Dutch, and oral story-telling could not be included in the model because of multicollinearity with intensity of exposure.

The findings of this study are in line with previous studies that show that book-reading has a positive effect on children's language acquisition (Bus et al., 1995; Mol \& Bus, 2011; Mol et al., 2008), whereas watching TV does not (Hudon et al., 2013; Patterson, 2002; Schmidt et al., 2009; Zimmermann et al., 2007). They confirm that, in bilingual children, reading activities can stimulate vocabulary acquisition in both languages (Patterson, 2002; Scheele et al., 2010) and that reading can also enhance grammatical development (Crain-Thoreson \& Dale, 1992; Cronan et al., 1996; Sénéchal et al., 2008; Whitehurst et al., 1988). A possible explanation for the effect of book-reading on bilingual language acquisition is the great lexical and syntactic diversity in books (Montag et al., 2015; Noble et al., 2018). As the diversity of words and syntactic structures that children hear has a direct effect on their language development (Huttenlocher et al., 2010; Rowe, 2012), this may well explain why book-reading is so important for children's language development.

As far as we know, this is the first study that investigated the effect of language activities on the grammatical development of bilingual children in both of their languages. The finding that book-reading had an effect on Frisian, but not on Dutch, morphology shows that this language activity is especially important for the grammatical development of the minority language. Previous research has shown that even Frisian-speaking children in the higher grades of primary school have not yet fully mastered Frisian nominal and verbal morphology (Ytsma, 1995). A possible reason for this late acquisition is that the amount and diversity of Frisian input is relatively limited. While all children receive frequent and diverse exposure to Dutch through education, input in Frisian depends more strongly on the language situation at home. When parents read Frisian books with their children, they improve the diversity of Frisian input that their children are exposed to. The current study shows that this has a positive effect on Frisian language acquisition in general and the acquisition of Frisian morphology in particular. It is a topic for future research whether the acquisition of other aspects of Frisian grammar can also be stimulated by book-reading. 
The effect of book-reading at home on bilingual children's language acquisition lines up with previous research on the effect of input quantity at home. Just like book-reading, input quantity has also been shown to be more important for the acquisition of Frisian than for the acquisition of Dutch, which can also be learned outside the home (Bosma, Hoekstra, Versloot, \& Blom, 2017; Dijkstra et al., 2016; Van Ruijven, 2006; Ytsma, 1995, 1999). That input quantity is more important for the minority language than for the majority language has not only been shown in the Frisian-Dutch bilingual context, but also with other language pairs (De Houwer, 2007; Gathercole \& Thomas, 2009; Hammer et al., 2009). To our knowledge, however, this is the first study that shows that book-reading at home is also more important for the minority language. This is a relevant insight, because it shows that diverse language input at home is especially important when the home language is only used to a limited extent outside the home, such as in a minority-majority language context. Future research should investigate whether language activities in the home are even more important for heritage languages, which are exclusively spoken in the home. The results of our study thus stress the important role that parents play in the acquisition of the minority language: by reading books in Frisian they can stimulate the Frisian language acquisition of their children. As the future of a language depends on passing on the language to new generations, the insights of this study may be relevant for the continued existence of minority languages like Frisian.

It is a limitation of the current study that we only globally investigated children's participation in book-reading, oral story-telling, and watching TV. We did not collect information about the specific types of books, stories, and TV programmes that children were exposed to, nor the way parents interacted with their children during these activities. This could be important for future research, given that book-reading is especially stimulating when it is interactive (Mol et al., 2008) and that the effect of watching TV depends on the specific programmes that children watch (Linebarger \& Walker, 2005; Wright et al., 2001). Storybook-type programmes and educational programmes where characters directly speak to the child, label objects, and invite children to respond were found to be positively associated with vocabulary development (Linebarger \& Walker, 2005; Wright et al., 2001). In contrast, programmes that are not intended for children (Hudon et al., 2013) and programmes with loose narrative structure or poor language models (Linebarger \& Walker, 2005) were found to be negatively associated with vocabulary development. These studies suggest that watching TV can have a positive effect on children's language acquisition, as long as there is an interactive component that stimulates the participation of the child. With respect to oral story-telling, observations or more detailed questions about different types of oral story-telling may reduce the risk of multicollinearity with intensity of exposure and may provide a more fine-grained picture of the specific types of conversations that are most beneficial for bilingual language acquisition. Taking these things together, the main finding of this study is that, in a language context with a minority and a majority language, shared book-reading at home is especially important for the acquisition of the minority language. In the FrisianDutch bilingual context, we found that book-reading in Frisian stimulated the acquisition of both Frisian vocabulary and Frisian morphology, whereas book-reading in Dutch only stimulated Dutch vocabulary, and not Dutch morphology. As Frisian morphology is known to be a vulnerable domain in children's language acquisition (Ytsma, 1999), this shows that reading activities in the home can stimulate the acquisition of the more vulnerable aspects of a minority language. 
Author ORCIDs. (D) Evelyn Bosma, 0000-0001-8550-3720

Acknowledgments. This work was supported by the European Union's Seventh Framework Programme for research, technological development, and demonstration under grant agreement no. 613465. The data used in this article were gathered as part of a project that was supported by the Province of Fryslân, and that was conducted by the first author at the Fryske Akademy (Leeuwarden, The Netherlands) and the University of Amsterdam. We would like to thank the children, parents, and schools who participated in this study, and Paula van Zwol and Rixt Weiland, who assisted with data collection.

\section{References}

Beals, D. (2001). Eating and reading: links between family conversations with preschoolers and later language and literacy. In D. K. Dickinson \& P. O. Tabors (Eds.), Beginning literacy with language: young children learning at home and school (pp. 75-92). Baltimore, MD: Paul H. Brookes.

Blom, E., \& Bosma, E. (2016). The sooner the better? An investigation into the role of age of onset and its relation with transfer and exposure in bilingual Frisian-Dutch children. Journal of Child Language, 43 (3), 581-607.

Blom, E., Paradis, J., \& Duncan, T. S. (2012). Effects of input properties, vocabulary size, and L1 on the development of third person singular $-s$ in child L2 English. Language Learning, 62(3), 965-94.

Bosma, E., Blom, E., Hoekstra, E., \& Versloot, A. (2016). A longitudinal study on the gradual cognate facilitation effect in bilingual children's Frisian receptive vocabulary. International Journal of Bilingual Education and Bilingualism. retrieved from <https://doi.org/10.1080/13670050.2016.1254152>.

Bosma, E., Heeringa, W., Hoekstra, E., Versloot, A., \& Blom, E. (2017). Verbal working memory is related to the acquisition of cross-linguistic phonological regularities. Frontiers in Psychology, 8, 1487. Retrieved from <https://doi.org/10.3389/fpsyg.2017.01487> .

Bosma, E., Hoekstra, E., Versloot, A., \& Blom, E. (2017). The minimal and short-lived effects of minority language exposure on the executive functions of Frisian-Dutch bilingual children. Frontiers in Psychology, 8, 1453. Retrieved from <https://doi.org/10.3389/fpsyg.2017.01453> .

Breuker, P. (2001). West Frisian in language contact. In H. H. Munske, N. Århammar, V. F. Faltings, J. F. Hoekstra, O. Vries, A. G. H. Walker, \& O.Wilts (Eds.), Handbook of Frisian studies (pp. 121-9). Tübingen: Max Niemeyer.

Bus, A. G., Van IJzendoorn, M. H., \& Pellegrini, A. D. (1995). Joint book reading makes for success in learning to read: a meta-analysis on intergenerational transmission of literacy. Review of Educational Research, 65(1), 1-21.

Centraal Bureau voor Statistiek (2018). Bevolkingsontwikkeling; regio per maand [Data file]. Retrieved from $<$ http://statline.cbs.nl/Statweb/publication/?DM=SLNL\&PA=37230ned\&D1=0-2,4-5,7-8,13-17\&D2=6, 20-22\&D3=1,40,105,170,183,1\&VW=T> (last accessed 20 February 2018).

Chonchaiya, W., \& Pruksananonda, C. (2008). Television viewing associates with delayed language development. Acta Paediatrica, 97(7), 977-82.

Crain-Thoreson, C., \& Dale, P. S. (1992). Do early talkers become early readers? Linguistic precocity, preschool language, and emergent literacy. Developmental Psychology, 28(3), 421-9.

Cronan, T. A., Cruz, S. G., Arriaga, R. I., \& Sarkin, A. J. (1996). The effects of a community-based literacy program on young children's language and conceptual development. American Journal of Community Psychology, 24(2), 251-72.

Curenton, S. M., Craig, M. J., \& Flanigan, N. (2008). Use of decontextualized talk across story contexts: how oral storytelling and emergent reading can scaffold children's development. Early Education and Development, 19(1), 161-87.

DeBaryshe, B. D. (1993). Joint picture-reading correlates of early oral language skill. Journal of Child Language, 20(2), 455-61.

De Graaf, T., Van der Meer, C., \& Karsten, E. (2013). Multilingualism and language teaching in Europe: the case of Frisian and the work of the Mercator European Research Centre. In E. Karsten \& T. de Graaf (Eds.), Sustaining indigenous knowledge: learning tools and community initiatives for preserving endangered languages and local cultural heritage (pp. 17-34). Fürstenberg/Havel: Kulturstiftung Sibirien.

De Houwer, A. (2007). Parental language input patterns and children's bilingual use. Applied Psycholinguistics, 28(3), 411-24. 
Demir, Ö. E., Rowe, M. L., Heller, G., Goldin-Meadow, S., \& Levine, S. C. (2015). Vocabulary, syntax, and narrative development in typically developing children and children with early unilateral brain injury: early parental talk about the 'there-and-then' matters. Developmental Psychology, 51(2), 161-75.

Dijkstra, J. (2013). Growing up with Frisian and Dutch: the role of language input in the early development of Frisian and Dutch among preschool children in Friesland (Doctoral dissertation). Leeuwarden: Fryske Akademy.

Dijkstra, J., Kuiken, F., Jorna, R. J., \& Klinkenberg, E. L. (2016). The role of majority and minority language input in the early development of a bilingual vocabulary. Bilingualism: Language and Cognition, 19(1), 191-205.

Dunn, L. M., \& Dunn, L. M. (1997). Peabody Picture Vocabulary-third edition. Circle Pines, MN: AGS.

Farrant, B. M., \& Zubrick, S. R. (2012). Early vocabulary development: the importance of joint attention and parent-child book reading. First Language, 32(3), 343-64.

Farrant, B. M., \& Zubrick, S. R. (2013). Parent-child book reading across early childhood and child vocabulary in the early school years: findings from the Longitudinal Study of Australian Children. First Language, 33(3), 280-93.

Field, A. (2000). Discovering statistics using SPSS statistics (3rd ed.). London: Sage.

Fletcher, K. L., Cross, J. R., Tanney, A. L., Schneider, M., \& Finch, W. H. (2008). Predicting language development in children at risk: the effects of quality and frequency of caregiver reading. Early Education and Development, 19(1), 89-111.

Gathercole, V. C. M., \& Thomas, E. M. (2009). Bilingual first-language development: dominant language takeover, threatened minority language take-up. Bilingualism: Language and Cognition, 12(2), 213-37.

Gooskens, C., \& Heeringa, W. (2004). The position of Frisian in the Germanic language area. In D. Gilbers, M. Schreuder, \& N. Knevel (Eds.), On the boundaries of phonology and phonetics (pp. 61-87). University of Groningen.

Hammer, C. S., Davison, M. D., Lawrence, F. R., \& Miccio, A. W. (2009). The effect of maternal language on bilingual children's vocabulary and emergent literacy development during Head Start and kindergarten. Scientific Studies of Reading, 13(2), 99-121.

Hoff, E. (2003). The specificity of environmental influence: socioeconomic status affects early vocabulary development via maternal speech. Child Development, 74(5), 1368-78.

Hoff, E. (2006). How social contexts support and shape language development. Developmental Review, 26 (1), 55-88.

Hogan-Brun, G., \& Wolff, S. (2003). Minority languages in Europe: an introduction to the current debate. In G. Hogan-Brun \& S. Wolff (Eds.), Minority languages in Europe (pp. 3-15). London: Palgrave Macmillan.

Houston-Price, C., Howe, J. A., \& Lintern, N. J. (2014). Once upon a time, there was a fabulous funambulist ...: what children learn about the 'high-level' vocabulary they encounter while listening to stories. Frontiers in Psychology, 5, 75. Retrieved from <https://doi.org/10.3389/fpsyg.2014.00075> .

Hudon, T. M., Fennell, C. T., \& Hoftyzer, M. (2013). Quality not quantity of television viewing is associated with bilingual toddlers' vocabulary scores. Infant Behavior and Development, 36(2), 245-54.

Huttenlocher, J., Waterfall, H., Vasilyeva, M., Vevea, J., \& Hedges, L. V. (2010). Sources of variability in children's language growth. Cognitive Psychology, 61(4), 343-65.

Katz, J. R. (2001). Playing at home: the talk of pretend play. In D. K. Dickinson \& P. O. Tabors (Eds.), Beginning literacy with language: young children learning at home and school (pp. 53-74). Baltimore, MD: Paul H. Brookes.

Khu, M., Graham, S. A., \& Ganea, P. (2014). Learning from picture books: infants' use of naming information. Frontiers in Psychology, 5, 144. Retrieved from <https://doi.org/10.3389/fpsyg.2014.00144> .

Linebarger, D. L., \& Walker, D. (2005). Infants' and toddlers' television viewing and language outcomes. American Behavioral Scientist, 48(5), 624-45.

Mercator European Research Centre on Multilingualism and Language Learning (2007). The Frisian language in education in the Netherlands. Leeuwarden: Fryske Akademy.

Mol, S. E., \& Bus, A. G. (2011). To read or not to read: a meta-analysis of print exposure from infancy to early adulthood. Psychological Bulletin, 137(2), 267-96.

Mol, S. E., Bus, A. G., De Jong, M. T., \& Smeets, D. J. (2008). Added value of dialogic parent-child book readings: a meta-analysis. Early Education and Development, 19(1), 7-26. 
Montag, J. L., Jones, M. N., \& Smith, L. B. (2015). The words children hear: picture books and the statistics for language learning. Psychological Science, 26(9), 1489-96.

Mundy, P., Sigman, M., Ungerer, J., \& Sherman, T. (1986). Defining the social deficits of autism: the contribution of non-verbal communication measures. Journal of Child Psychology and Psychiatry, 27(5), 657-69.

National Center for Family Literacy (2008). Developing early literacy: report of the National Early Literacy Panel: a scientific synthesis of early literacy development and implications for intervention. Washington, DC: National Institute for Literacy.

Noble, C. H., Cameron-Faulkner, T., \& Lieven, E. (2018). Keeping it simple: the grammatical properties of shared book reading. Journal of Child Language, 45(3), 753-66.

Paradis, J. (2011). Individual differences in child English second language acquisition: comparing child-internal and child-external factors. Linguistic Approaches to Bilingualism, 1(3), 213-37.

Paradis, J., Emmerzael, K., \& Sorenson Duncan, T. (2010). Assessment of English language learners: using parent report on first language development. Journal of Communication Disorders, 43, 474-97.

Patterson, J. L. (2002). Relationships of expressive vocabulary to frequency of reading and television experience among bilingual toddlers. Applied Psycholinguistics, 23(4), 493-508.

Pearson, B. Z. (2007). Social factors in childhood bilingualism in the United States. Applied Psycholinguistics, 28(3), 399-410.

Pearson, B. Z., Fernández, S. C., \& Oller, D. K. (1993). Lexical development in bilingual infants and toddlers: comparison to monolingual norms. Language Learning, 43(1), 93-120.

Prevoo, M. J., Malda, M., Mesman, J., Emmen, R. A., Yeniad, N., Van IJzendoorn, M. H., \& Linting, M. (2014). Predicting ethnic minority children's vocabulary from socioeconomic status, maternal language and home reading input: different pathways for host and ethnic language. Journal of Child Language, 41 (5), 963-84.

Provinsje Fryslân (2015). De Fryske Taalatlas 2015. Fryske Taal yn Byld. Leeuwarden: Provinsje Fryslân.

Reese, E. (1995). Predicting children's literacy from mother-child conversations. Cognitive Development, 10(3), 381-405.

Rice, M. L., \& Hoffman, L. (2015). Predicting vocabulary growth in children with and without specific language impairment: a longitudinal study from 2;6 to 21 years of age. Journal of Speech, Language, and Hearing Research, 58(2), 345-59.

Rowe, M. L. (2012). A longitudinal investigation of the role of quantity and quality of child-directed speech in vocabulary development. Child Development, 83(5), 1762-74.

Rowe, M. L. (2013). Decontextualized language input and preschoolers' vocabulary development. Seminars in Speech and Language, 34(4), 260-6.

Scheele, A. F., Leseman, P. P., \& Mayo, A. Y. (2010). The home language environment of monolingual and bilingual children and their language proficiency. Applied Psycholinguistics, 31(1), 117-40.

Schlichting, L. (2005). Peabody Picture Vocabulary Test-III-NL. Amsterdam: Harcourt Test Publishers.

Schmidt, M. E., Rich, M., Rifas-Shiman, S. L., Oken, E., \& Taveras, E. M. (2009). Television viewing in infancy and child cognition at 3 years of age in a US cohort. Pediatrics, 123(3), e370-e375.

Sénéchal, M. (1997). The differential effect of storyreading on preschoolers' acquisition of expressive and receptive vocabulary. Journal of Child language, 24(1), 123-38.

Sénéchal, M., Pagan, S., Lever, R., \& Ouellette, G. P. (2008). Relations among the frequency of shared reading and 4-year-old children's vocabulary, morphological and syntax comprehension, and narrative skills. Early Education and Development, 19(1), 27-44.

Thordardottir, E., Rothenberg, A., Rivard, M. E., \& Naves, R. (2006). Bilingual assessment: Can overall proficiency be estimated from separate measurement of two languages? Journal of Multilingual Communication Disorders, 4(1), 1-21.

Tomasello, M., \& Farrar, M. J. (1986). Joint attention and early language. Child Development, 57(6), 1454-63.

Tuller, L. (2015). Clinical use of parental questionnaires in multilingual contexts. In S. Armon-Lotem, J. de Jong, \& N. Meir (Eds.), Assessing multilingual children: disentangling bilingualism from language impairment (pp. 301-30). Bristol: Multilingual Matters.

Uccelli, P., Demir-Lira, Ö. E., Rowe, M. L., Levine, S., \& Goldin-Meadow, S. (2018). Children's early decontextualized talk predicts academic language proficiency in midadolescence. Child Development. Retrieved from <https://doi.org/10.1111/cdev.13034>. 
Uccelli, P., \& Páez, M. M. (2007). Narrative and vocabulary development of bilingual children from kindergarten to first grade: developmental changes and associations among English and Spanish skills. Language, Speech, and Hearing Services in Schools, 38(3), 225-36.

Van Ruijven, E. C. M. (2006). Leervorderingen in het Friese basisonderwijs: Onderzoek naar het onderwijsniveau en de leervorderingen van de leerlingen in het Friese basisonderwijs. Leeuwarden: Fryske Akademy.

Van Ruijven, E. C. M., \& Ytsma, J. (2008). Trijetalige Skoalle yn Fryslân. Leeuwarden: Fryske Akademy.

Verhoeven, L., \& Vermeer, A. (2002). Taaltoets Alle Kinderen. Tilburg: Zwijsen.

Wechsler, D., \& Naglieri, J. A. (2006). Wechsler Nonverbal Scale of Ability. San Antonio, TX: Pearson.

Whitehurst, G. J., Falco, F. L., Lonigan, C. J., Fischel, J. E., DeBaryshe, B. D., Valdez-Menchaca, M. C., \& Caulfield, M. (1988). Accelerating language development through picture book reading. Developmental Psychology, 24(4), 552-9.

Wright, J. C., Huston, A. C., Murphy, K. C., St Peters, M., Piñon, M., Scantlin, R., \& Kotler, J. (2001). The relations of early television viewing to school readiness and vocabulary of children from low-income families: the early window project. Child Development, 72(5), 1347-66.

Ytsma, J. (1995). Frisian as first and second language: sociolinguistic and socio-psychological aspects of the acquisition of Frisian among Frisian and Dutch primary school children (Doctoral dissertation). Leeuwarden: Fryske Akademy.

Ytsma, J. (1999). Tweetaligheid bij kleuters in Friesland. In E. Huls and B. Weltens (Eds.), Artikelen van de Derde Sociolinguïstische Conferentie (pp. 497-508). Delft: Eburon.

Zimmerman, F. J., Christakis, D. A., \& Meltzoff, A. N. (2007). Associations between media viewing and language development in children under age 2 years. Journal of Pediatrics, 151(4), 364-8.

Cite this article: Bosma E, Blom E (2020). Language activities in a minority-majority language context: book-reading at home is more important for Frisian than for Dutch. Journal of Child Language 47, 289-308. https://doi.org/10.1017/S0305000919000023 